\title{
MAPEAMENTO DO USO E OCUPAÇÃO DA TERRA DO MUNICÍPIO DE ALCOBAÇA, BAHIA (2015)
}

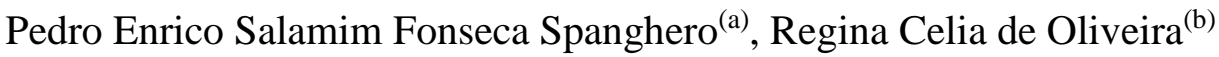 \\ (a) Instituto de Geociências, Universidade Estadual de Campinas, pedrospanghero@ig.unicamp.br; \\ (b) Instituto de Geociências, Universidade Estadual de Campinas, reginaoliveira@ige.unicamp.br;
}

\section{EIXO: USO E OCUPAÇÕES DAS TERRAS E LEGISLAÇÃO AMBIENTAL}

\begin{abstract}
Resumo
O mapeamento do uso e ocupação da terra é uma ferramenta auxiliar de suma importância no planejamento ambiental e na tomada de decisão. Sendo assim, o objetivo deste estudo foi gerar um Mapa de Uso e Ocupação da Terra na escala 1:30.000 para a totalidade do Município de AlcobaçaBahia, com aplicação de metodologia específica foram mapeadas 9 classes de uso e ocupação da terra por meio de imagens orbitais RapidEye do ano de 2015, seguida de trabalhos de campo para validação do mapeamento. Às áreas das classes utilizadas e seus respectivos percentuais, fornecem subsídios para futuros estudos de planejamento ambiental e ordenamento da paisagem do município. Como resultado, foram obtidos os percentuais de $0,25 \%$ de área urbanizada, $0,02 \%$ Área Urbanizada (rural), 2,96\% para Agricultura, 37,68\% para Pastagem, 37,33\% para Eucalipto, 0,42\% para Manguezal, 0,37\% Ảrea Úmida, $0,51 \%$ para Vegetação Arbustiva e 20,36\% para Vegetação Arbórea.
\end{abstract}

Palavra chave: Uso e ocupação da terra, Geoprocessamento, Mapeamento, Alcobaça/Bahia.

\section{Introdução}

Desde os primeiros agrupamentos humanos, a proximidade com o oceano e rios tem atraído diversos povos devido a grande disponibilidade de recursos continentais e marinhos, e proporcionando trocas comerciais com outros povos (DIAS, OLIVEIRA, 2012). Não diferente de outros exemplos ao longo do globo, no Brasil a ação de ocupação da costa vem ocorrendo desde longas datas, mas especificamente no município de Alcobaça, Bahia. Os primeiros colonos a chegarem nesta região datam do século XVIII, correspondendo desde este período a níveis diversos de intervenções humanas e alterações no funcionamento do sistema natural.

A partir desta perspectiva, a crescente ocupação dos ambientes costeiros tende a provar a alteração da dinâmica natural dos sistemas ambientais e a degradação dos ecossistemas. Neste sentido, as ações antrópicas despertam na sociedade a necessidade de realizar estudos científicos como meio de gerenciar, monitorar e educar o uso do espaço e com o objetivo de encontrar o equilíbrio entre o uso antrópico e a preservação do meio ambiente (MUEHE, 1998).

O conhecimento e o monitoramento do uso e ocupação da terra são de fundamental importância para a compreensão da organização da sociedade sobre a paisagem. O monitoramento consiste na busca de conhecimento de toda a sua utilização por parte da sociedade, a classificação de categorias de vegetação 
natural que reveste o solo e suas respectivas localizações. De forma sintética, a expressão "uso da terra" pode ser entendida como sendo a forma como a paisagem está sendo ocupada pelo homem. (ROSA, 2007)

Para Santos e Santos (2010), o mapeamento de uso e ocupação da terra tem sido considerado por muitos autores como uma importante ferramenta para melhor compreensão das rápidas transformações da paisagem, pois além de permitir a obtenção de informações para construção de cenários ambientais e indicadores, servirá também de subsídios práticos para a avaliação da capacidade de suporte ambiental, proporcionando assim o direcionamento de práticas conservacionistas aliadas a um conjunto de diferentes estratégias de manejo a serem empregadas.

O desenvolvimento de pesquisas na perspectiva da análise do uso e ocupação da terra consiste em compreender a dinâmica da relação entre sociedade x natureza e assim usar como suporte às decisões de planejamento e desenvolvimento sustentável.Nesse sentido,corrobora Araújo Filho et. AL. (2007), ao afirmar que a obtenção de informações detalhadas e precisas sobre o espaço geográfico é uma condição indispensável para a atividade de planejamento e nas tomadas de decisões, assim sendo o mapa de uso e ocupação da terra como um instrumento imprescindível que auxilia e promove a busca pelo planejamento ambiental.

Desta forma, definiu-se como objetivo deste trabalho a análise do uso e ocupação da terra do município de Alcobaça, Bahia no ano de 2015, na escala de 1:30.000 com imagens RapidEye e validação em campo.

\section{Caracterização da área de estudo}

O Brasil possui um dos maiores limites de costa do mundo, com cerca de $7.367 \mathrm{~km}$ extensão, e o litoral da Bahia se destaca por ser o maior litoral do país com uma extensão de $1.181 \mathrm{~km}$ com grandes potenciais culturais, náuticos, esportistas e ecoturísticos. Para fins de zoneamento foi elaborado em 1990 pelo Programa de Desenvolvimento Turístico da Bahia (PRODTEUR) uma regionalização do litoral baiano com o intuito de organizar intervenções públicas para o desenvolvimento de atividades turísticas através do planejamento regional, sendo dividida a área costeira em: Costa dos Coqueiros, Costa do Dendê, Costa do Cacau, Costa do Descobrimento e Costa das Baleias.

A Costa das Baleias, onde se localiza o município de Alcobaça, até meados da década de 1950 mantevese isolada, tendo como única forma de comunicação com as outras regiões a via marítima. A construção da BR-101 foi o marco para as transformações da paisagem da região com o desmatamento da Mata Atlântica e em seguida com o aparecimento da pecuária extensiva junto a implantação de novas culturas, como o coco-da-baía, mamão, maracujá, melancia e posteriormente a silvicultura e consolidação da pecuária de corte como principais receitas dos municípios da Costa das Baleias. Após diversas crises econômicas, o Governo Federal em conjunto com o Governo Estadual implantou na década de 1990 programas de incentivos fiscais para a instalação da industria e monocultura de eucalipto e planos de 


\section{OS DESAFIOS DA GEOGRAFIA FÍSICA NA FRONTEIRA DO CONHECIMENTO \\ Instituto de Geociências - Unicamp \\ Campinas - SP \\ 28 de Junho à 02 de Julho de 2017}

incentivo a indústria do turismo. A região hoje é uma das maiores responsáveis pela produção de eucalipto do Brasil .

Além de Alcobaça, a Costa das Baleias abrangende os municípios de Prado, Caravelas, Mucuri e Nova Viçosa (Figura 1). Alcobaça situa-se entre os paralelos $17^{\circ} 20^{\prime}$ e $17^{\circ} 40^{\prime}$ de latitude sul e os meridianos $39^{\circ} 10^{\prime}$ e $39^{\circ} 40^{\prime}$ de longitude oeste, limitando a norte pelo município de Prado, a oeste pelo município de Teixeira de Freitas, a sul pelo município de Caravelas e a leste pelo Oceano Atlântico e apresenta atualmente uma população de 21.271 habitantes (IBGE, 2010) e uma área de $1.480 \mathrm{~km}^{2}$.

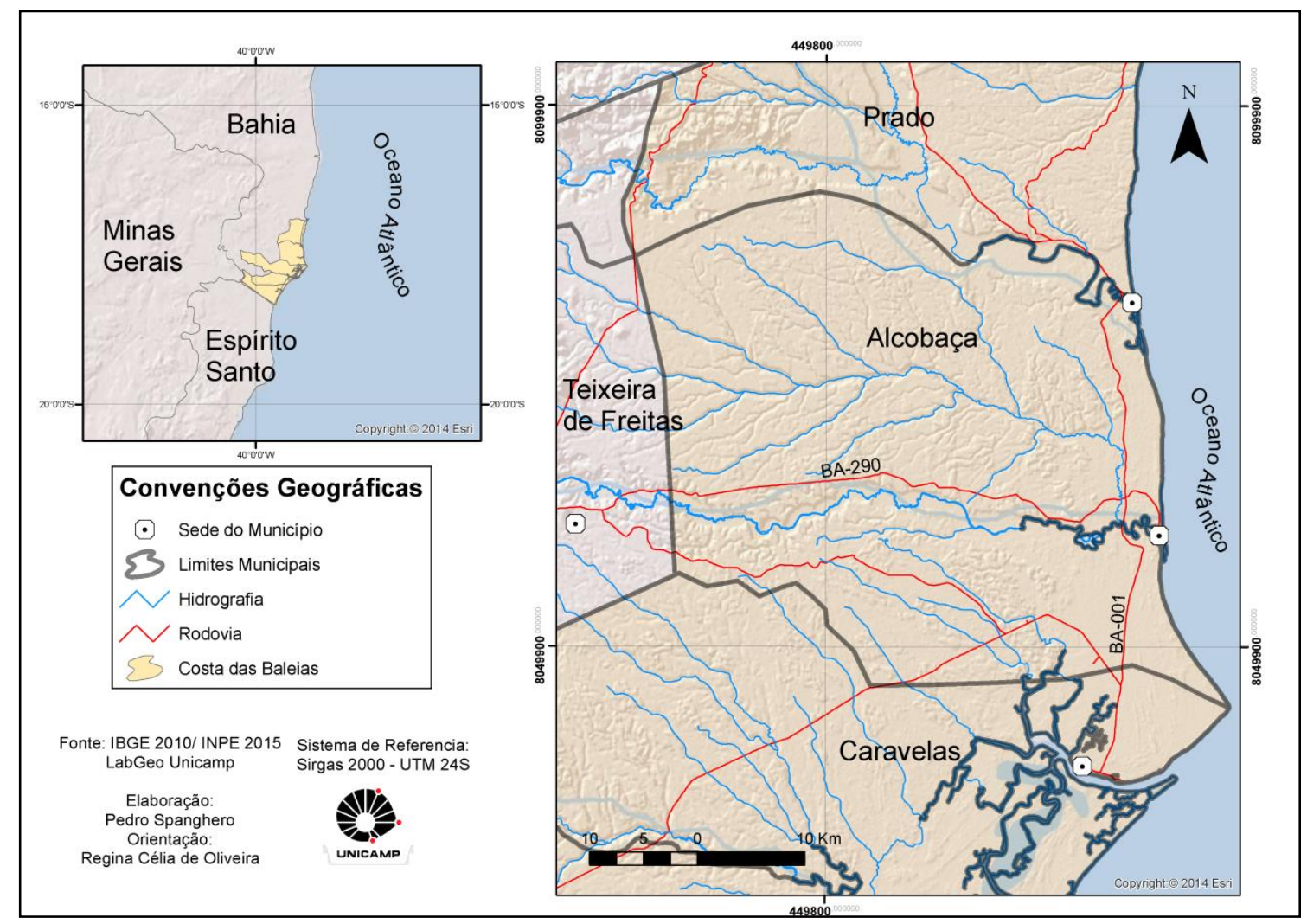

Figura 1. Localização do município de Alcobaça, Costa das Baleias, Bahia.

O clima do município é classificado como do tipo tropical, superúmido a úmido, sem estação seca (IBGE, 2010). O regime pluviométrico da área de estudo apresenta os maiores valores na costa e vão diminuindo em direção ao interior do município, tendo valores de $1400 \mathrm{~mm}$ ao ano na parte costeira e em áreas continentais os valores chegam até $1200 \mathrm{~mm}$ ao ano (SEI, 2010) .

Considerando as características geoambientais do município de Alcobaça, esta apresenta diversidades paisagísticas, refletidas não apenas no relevo e na cobertura vegetal, mas em todos os processos de formação e transformação da paisagem ocorridos nesta área para a sua configuração atual. 
O município de Alcobaça é caracterizado por apresentar dois grandes domínios geológicogeomorfológico, o Tabuleiro Costeiro composto por sedimentos areno-argilosos de idade Terciária da Formação Barreiras que se caracterizam pela existência de vales profundos e bordas escarpadas, e uma superfície geral inclinada em direção ao litoral. O outro domínio é a Planície Costeira, que apresenta sedimentos datados do Quaternário de origem marinha, incluindo-se nesse domínio os terraços marinhos, terras úmidas e praias, apresentando a formação de cordões litorâneos ao longo da planície costeira, em geral de composição arenosa formada pelas variações do nível do mar durante o Quaternário. (ANDRADE, DOMINGUEZ, 2002)

A formação dos solos está diretamente relacionada aos domínios geológico-geomorfológico da área de estudo. Para as áreas de tabuleiro costeiro há predominância dos solos Latossolo Amarelo Distrófico, já nas Planícies Fluviais e fluvio marinhas instalaram processos que originaram solos do tipo Gleissolo Háplico Eutrófico e Gleissolo Háplico e para a Planície Marinha onde há predominância de sedimentos arenosos implantaram-se os Neossolso Quartzarênicos(SEI, 2010).

\section{Metodologia}

Para a elaboração do mapeamento de uso e ocupação da terra foram desenvolvidas as seguintes etapas, descritas a seguir (Figura 2.). 


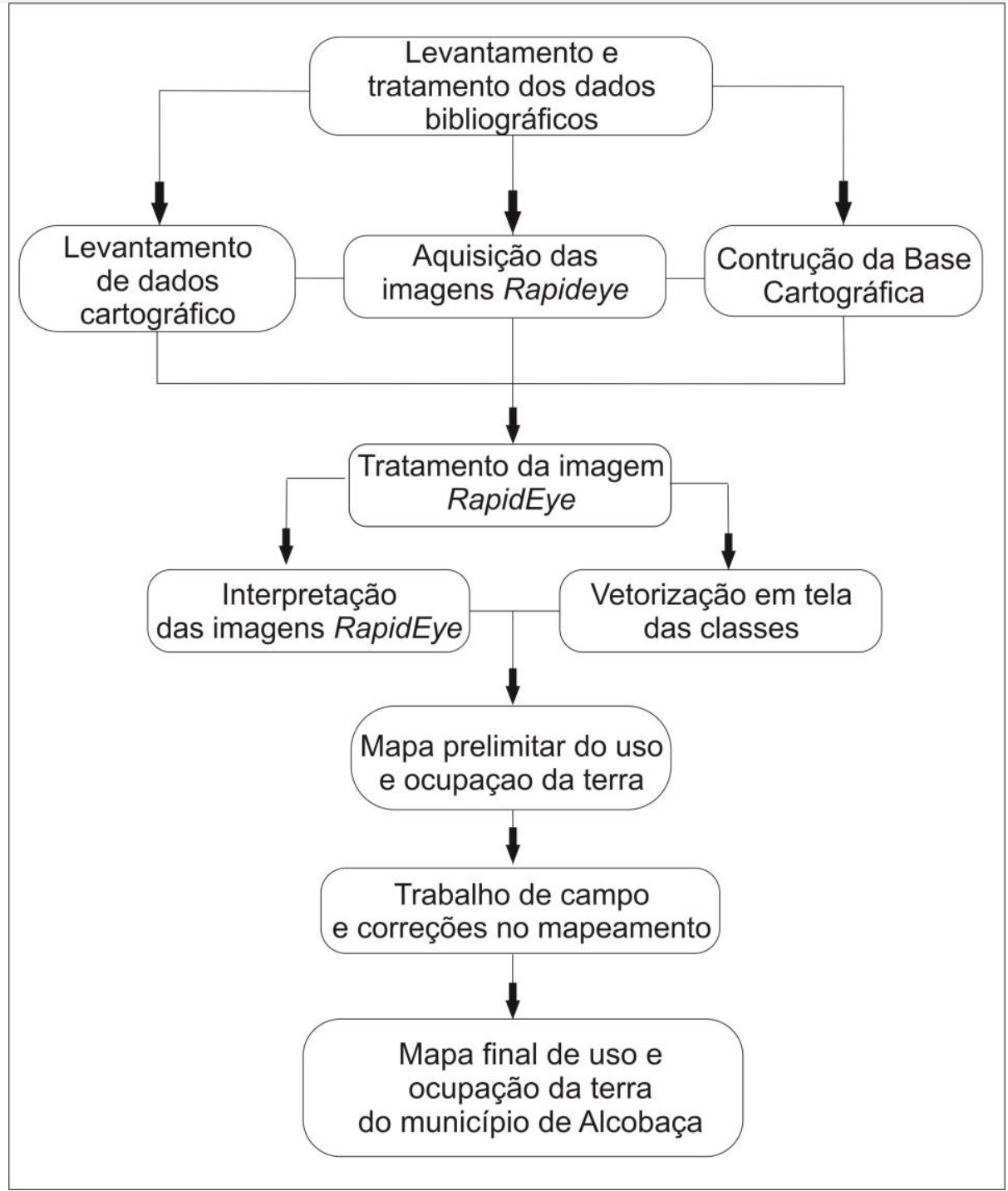

Figura 2. Fluxograma esquematizado das etapas metodológica do mapeamento do uso e ocupação da terra.

Foi realizado o levantamento bibliográfico de informações pretéritas sobre atividades econômicas, formação e histórico da formação da região Costa das Baleias, referências teórico-metodológicas e classificação de uso e ocupação da terra.

O levantamento cartográfico envolveu a aquisição das folhas topográficas na escala de 1:100.000 de Prado (SE.24-V-B-VI 2356), Itamaraju (SE.24-V-D-II 2355), Teixeira de Freitas (SE.24-V-D-V-II 2393) e Caravelas (SE-24-V-D-VI 2394) e dos shapefile de rodovias e hidrografia para a composição final da base de dados. Utilizando o Sistema de Informação Geográfica (SIG), ArcGis 10.4, no datum Sirgas 2000, UTM 24S no desenvolvimento de todo o trabalho.

Na elaboração do mapeamento de uso da terra foram utilizadas imagens de satélite Rapideye, na composição 1, 2, 3 do ano de 2015, disponibilizado pelo Ministério do Meio Ambiente, com resolução espacial de 05 metros. Para melhorar a qualidade da imagem foram aplicadas técnicas de contraste com o 


\section{OS DESAFIOS DA GEOGRAFIA FÍSICA NA FRONTEIRA DO CONHECIMENTO \\ Instituto de Geociências - Unicamp \\ Campinas - SP \\ 28 de Junho à 02 de Julho de 2017}

objetivo de aumentar a discriminação visual dos objetos e correção geométrica para eliminar prováveis distorções na imagem.

A interpretação da imagem consistiu na identificação dos tipos de uso e ocupação da terra, sendo realizada a vetorização seguindo a interpretação da imagem de satélite de acordo com as características de cor, textura, tamanho, forma e localização. As classes foram selecionadas para serem mapeadas a partir do conhecimento prévio da área de estudo e foram definidas as seguintes classes: Área Urbanizada, Área Urbana (Rural), Agricultura, Pastagem, Eucalipto, Manguezal, Terras Úmidas, Vegetação Arbustiva, Vegetação Arbórea.

A princípio, foi elaborado um mapa preliminar com o objetivo de nortear a atividade de campo, que consistiu em validar as informações obtidas em laboratório, ocorrendo no total dois campos, o primeiro no dia 21 de dezembro de 2016 e o segundo dia 13 de janeiro de 2017. Durante o trabalho de campo foram coletados diversos pontos de GPS e fotografias, bem como a descrição da paisagem, observando os conflitos socioambientais e caracterizando diversos tipos de usos e ocupações da terra.

\section{Resultados e Discussão}

A tabela 1 e a figura 3 apresentam a quantificação e percentagem das classes de uso e ocupação da terra da área de estudo definidas em 9 tipos de classes:

1. Área Urbanizada - cidade;

2. Área Urbanizada (Rural) - comunidades e pequenos centros urbanos;

3. Agricultura - constituído principalmente por culturas de subsistências, maracujá, melancia, mamão e coco-da-baía.

4. Pastagem - área antropizada;

5. Eucalipto - silvicultura;

6. Manguezal;

7. Área Úmida - brejos, várzea.

Á área total do município de Alcobaça é de aproximadamente $1.478 \mathrm{~km}^{2}$. A forma de uso predominante na bacia é pastagem, com 37,68\%, eucalipto com 37,33\%, vegetação arbórea 20,36\%, agricultura 2,96\%, vegetação arbustiva $0,51 \%$, manguezal $0,42 \%$, área úmida $0,37 \%$, área urbanizada $0,25 \%$ e área urbanizada (rural) $0,02 \%$.

Tabela 1. Quantificação das classes de uso e ocupação da terra do município de Alcobaça, Bahia - 2015.

\begin{tabular}{ccc}
\hline Uso do Solo & $\begin{array}{c}\text { Área } \\
\mathbf{( k m}^{\mathbf{2}} \mathbf{)}\end{array}$ & $\begin{array}{c}\text { \% Relativa ao } \\
\text { Total }\end{array}$ \\
\hline Área Urbanizada & 3,8 & 0,25 \\
Área Urbanizada (Rural) & 0,3 & 0,02 \\
Agricultura & 43,9 & 2,96 \\
Pastagem & 557,7 & 37,68 \\
\hline
\end{tabular}




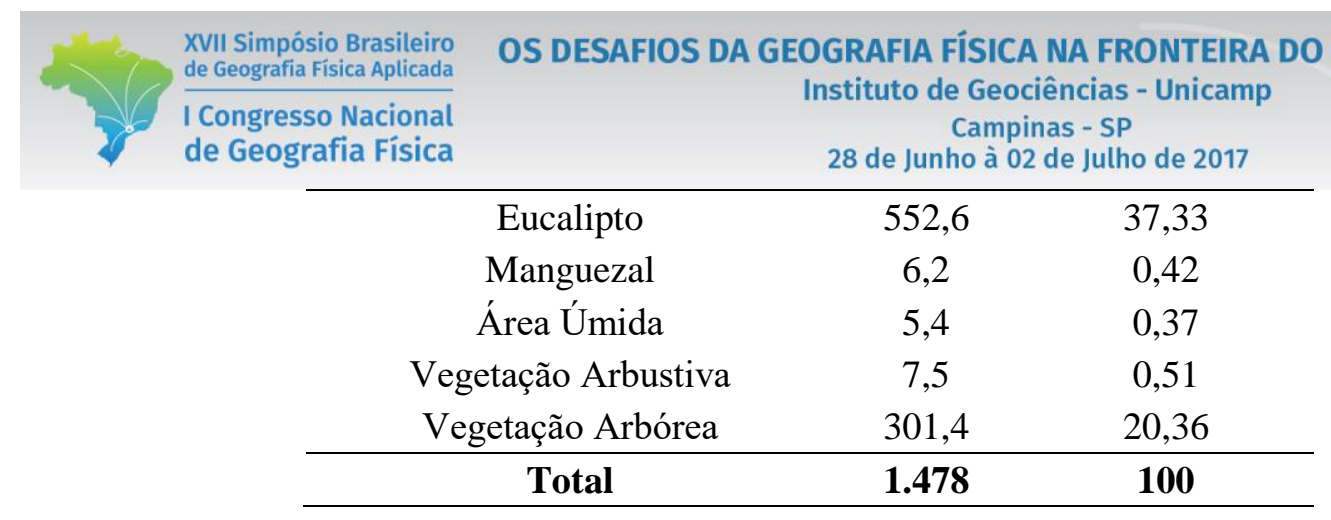
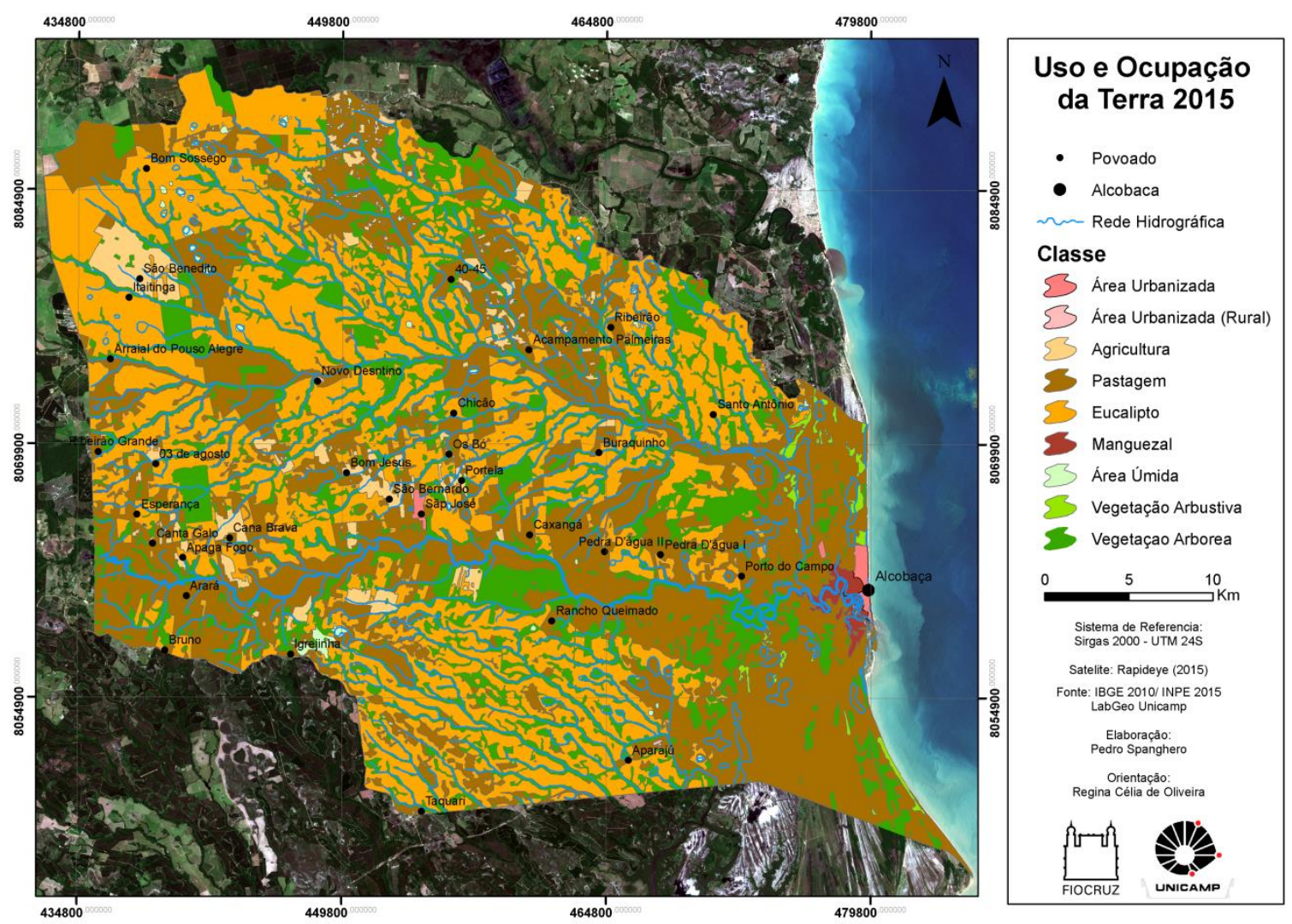

Figura 3. Uso e ocupação da terra do município de Alcobaça, Bahia - 2015.

A área urbanizada (sede)e a área urbanizada (rural) ocupam juntas aproximadamente $4,1 \mathrm{~km}^{2}(0,27 \%)$ do total do município, correspondendo a cidades e comunidades. Foram identificadas 31 comunidades que se concentram principalmente na parte interiorana do município,onde há predomínio da atividade agropastoril, em sua maior parte de subsistência. Os produtos oriundos dessas comunidades são transportados para a sede municipal de Alcobaça ou são enviados para serem vendidos na principal cidade da região, Teixeira de Freitas, utilizando como meio de deslocamento a rodovia BA-290.

A agricultura corresponde a 43,9 $\mathrm{km}^{2}(2,96 \%)$ de todo município de Alcobaça, e compreende principalmente os cultivos de café, mamão, melancia, mandioca, coco-da-baía e culturas de subsistência.

O eucalipto corresponde a $552,6 \mathrm{~km}^{2}$ (37,33\%),onde a utilização do solo é intensa e constante, com grande processo de mecanização e pressão sobre os pequenos agricultores por utilizarema maior parte das áreas agricultáveis do município. Em muitas áreas do município há o emprego excessivo de defensivos 
XVII Simpósio Brasileiro

de Geografia Fisica Aplicada

I Congresso Nacional

de Geografia Física

\section{OS DESAFIOS DA GEOGRAFIA FÍSICA NA FRONTEIRA DO CONHECIMENTO \\ Instituto de Geociências - Unicamp \\ Campinas - SP \\ 28 de Junho à 02 de Julho de 2017}

agrícolas que vem causando problemas ambientais, como a contaminação do solo e a eutrofização de ambientes aquáticos. Desta forma, torna-se urgente o uso de técnicas e ações voltadas para o manejo agrícola mais consciente e adequado e a necessidade de fiscalização e monitoramento das áreas agrícolas.

A pastagem corresponde a $557,7 \mathrm{~km}^{2}(37,68 \%)$ de extensão, sendo este o principal uso da terra do município. As terras com pastagem são utilizadas principalmente com a pecuária bovina extensiva de corte voltada para o mercado regional. $\mathrm{O}$ uso da terra com pastagem provoca problemas ambientais como pisoteio do solo pelo gado, compactando-o e reduzindo a capacidade de infiltração da água. Com a retirada da vegetação, o solo fica desprotegido e o efeito splash torna-se mais forte, causando rupturas e acelerando os processos erosivos.

Manguezal representa uma área de $6,2 \mathrm{~km}^{2}(0,42 \%)$, mas é de grande importância por ser um ecossistema associado da Mata Atlântica e que recebe diretamente o efeito da ação marinha, tendo suas raízes como fixadores do material depositado pelo rio e mar. Além de ser fundamental para a atividade pesqueira por ser um berçário de inúmeras espécies de peixes e crustáceos, é tido como uma valiosa fonte de renda para o município de Alcobaça.

Área úmida corresponde a $5,4 \mathrm{~km}^{2}(0,37 \%)$, composto principalmente por brejos e várzeas localizadas em campo com pontos de GPS. As áreas úmidas do município são periodicamente ou permanentemente inundadas por água doce ou salobra e possuem grande importância na questão ambiental por proporcionar a contenção de inundações, recargas de aquíferos em períodos de seca, retenção de nutrientes e purificação da água.

Vegetação arbustiva compõe $7,5 \mathrm{~km}^{2}(0,51 \%)$ do município e corresponde a fragmentos da Mata Atlântica que sofreram com o processo de antropização e corte seletivo de árvores. Atualmente apresentam-se em processo de regeneração.

Vegetação Arbórea representa $301,4 \mathrm{~km}^{2}$ (20,36\%) do total das terras do município. Essa classe é composta por boa parte de fragmentos preservados da Mata Atlântica, entretanto grande parte desses fragmentos está sofrendo pressão antrópica em decorrência de suas valiosas madeiras de lei ótimas para a construção de móveis e construção naval. Em campo foram notadas diversas áreas protegidas devido à vontade dos respectivos proprietários em ter a Mata Atlântica por compreender a sua importância ambiental. Entretanto, não há qualquer segurança legal em relação à continuação destas florestas, já que a fiscalização ambiental é ineficaz e não há qualquer tipo de unidade de conservação publica ou privada na parte continental do município que possa garantir a preservação ao longo dos anos.

Nos trabalhos de campo foram comprovados diversos impactos ambientais, como a supressão gradativadas áreas de preservação permanente (APPs), derrubada da mata nativa, aterro de mangues e terras úmidas para práticas agropecuárias e descarte irregular de lixo. 


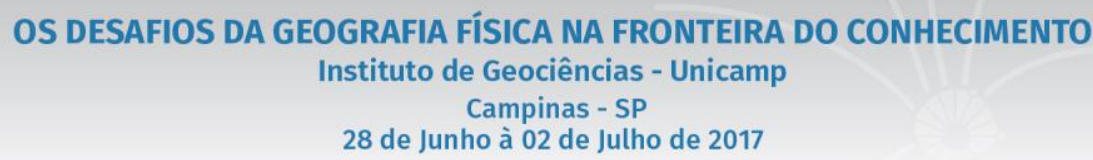

O município de Alcobaça, assim como muitos outros, carece de ações efetivas e contundentes do poder público que vise o desenvolvimento sustentável e a preservação da natureza, bem como uma fiscalização adequada que possibilite responsabilizar as práticas ilegais desenvolvidas na localidade, como o desmatamento, retirada ilegal de areia, caça, aterro do mangue e das áreas úmidas. É de essencial importância a elaboração de planos concretos e firmes que norteiam a expansão da agropecuária, silvicultura e expansão urbana de forma consciente e com respeito ao meio ambiente.

\section{Conclusão}

O mapeamento do uso e ocupação da terra evidenciou o forte processo de antropização e ocupação da terra pela pastagem e eucalipto, representando mais de $70 \%$ da área total do município de Alcobaça. A elaboração deste trabalho utilizando imagens RapidEye mostrou-se eficaz pelo excelente nível de detalhamento na identificação das classes de uso. As atividades de campo desenvolvidas na área de estudo foram de fundamental importância para a identificação/validação de classes e a compreensão melhor de como se dá a dinâmica da paisagem na relação estreita da natureza $\mathrm{x}$ sociedade no município de Alcobaça.

Levantamentos futuros nesta temática fornecerão subsídios para monitorar e analisar a mudança do uso e ocupação do solo, avaliando os impactos ambientais que servirão de base para a elaboração de um planejamento ambiental cada vez mais eficaz.

\section{Agradecimentos}

Os autores agradecem à Coordenação de Aperfeiçoamento de Pessoal de Nível Superior - CAPES pela disponibilidade da bolsa de estudos, Universidade Estadual de Campinas - Unicamp pela estrutura e a Fundação Oswaldo Cruz - Fiocruz pelo apoio na pesquisa.

\section{Bibliografia}

ANDRADE, A. C. S.; DOMINGUEZ J. M. L. Informações Geológico-Geomorfológicas como Subsídios a Análise Ambiental: o Exemplo da Região Planície Costeira de Caravelas - Bahia. Boletim Paranaense de Geociências, Curitiba. n. 51, p.9-17, 2002.

ARAÚJO FILHO, M. da C.; MENESES, P. R.; SANO, E. E. Sistema de classificação de uso e cobertura da Terra na análise de imagens de satélite. Revista Brasileira de Cartografia. n. 59/02, ago. 2007

DIAS, R. L.; OLIVEIRA, R. C. Análise das paisagens do litoral sul do estado de São Paulo. Revista Sociedade \& Natureza, n. 3, set/dez. 2012.

IBGE - Instituto Brasileiro de Geografia e Estatística. Disponível em: www.ibge.gov.br. Acesso em: 10 de jan.2017. MUEHE, G. de C. O Litoral Brasileiro e sua compartimentação. In: Cunha, S.B. e GUERRA, A. Geomorfologia do Brasil. Rio de Janeiro: Editora Bertrand Brasil S. A., 1998. p. 273-349

Rosa, R. Introdução ao sensoriamento remeto. Uberlândia: Ed. UFU, 2007. 248 p.

SANTOS, A. L. C.; SANTOS, F. 2010. Mapeamento das classes de uso e cobertura do solo da bacia hidrográfica do rio Vaza-Barris, Sergipe. Revista Multidisciplinar da Uniesp: Saber Acadêmico, $\mathrm{n}^{\circ} 10$ - Dez.

SEI - Superintendência de Estudos Econômicos e Sociais da Bahia. Disponível em: www.sei.ba.gov.br. Acesso em: 02 de dez.2016. 